\title{
Pensononowoor
}

2019, vol. 82, 1-7

http://dx.doi.org/10.12657/denbio.082.001

\author{
Elias Milios, Charalampos Papalexandris
}

\section{Height growth of sprouts emerged from small stumps and seed origin saplings under shade, in low elevation Fagus sylvatica L. s.l. stands in Greece}

\author{
Received: 28 April 2017; Accepted: 21 July 2017
}

\begin{abstract}
The objectives of this study were a) to analyze the growth of seed origin saplings and young stump sprouts, emerged from small dimension stumps that were established and grew under different shade and site conditions in low elevation Fagus sylvatica L. s.l. stands, which are located in northeastern Greece, and b) to examine whether those stump sprouts can be incorporated in the regeneration process of beech stands growing in analogous marginal, for the species conservation conditions. Fifty-six seed and sprout origin saplings were cut. The sprouts had emerged from stumps having a basal diameter lower than $7 \mathrm{~cm}$. For each of the 56 saplings, the mean annual height increment was calculated, dividing the height of the sapling by the age of its base. The different shade regimes were determined using hemispherical photography. Sprouts, which grew in deep shade in both site types, and in the moderate shade in medium productivity sites, exhibited height growth analogous to seed origin plants growing under moderate and deep shade in good productivity sites, and under moderate shade in medium productivity sites. Moreover, even though it is of no practical significance, stump sprouts that were established and grew under moderate shade in good productivity sites, showed higher height growth rates than all the other (compared) categories of seed and sprout origin saplings. Consequently, sprouts can be used in various types and forms of shelterwood silvicultural systems where regeneration plants are established and grow under shade conditions. A few years after the emergence of sprouts, as regeneration cuttings proceed through the gradual removal of the mother trees, sprouts will probably exhibit high growth rates as a result of the improved light conditions and their pre-existing root system.
\end{abstract}

Keywords: beech, deep shade, moderate shade, regeneration

Address: E. Milios, C. Papalexandris, Department of Forestry and Management of the Environment and Natural Resources, Democritus University of Thrace, Pantazidou 193, 68200 Orestiada, Greece, e-mail: emilios@fmenr.duth.gr

\section{Introduction}

Sprouting is a plant trait that enables ecosystems to confront disturbances (Peterson \& Pickett, 1991; Masaka et al., 2004; Milios et al., 2014; Pausas et al., 2016; Batziou et al., 2017). It is strongly related to species persistence in a site against the new conditions created by disturbances (Bond \& Midgley, 2001; Papalexandris \& Milios, 2010). For this reason, sprouting ability has been proposed as a tool for the conservation of ecosystems against climate change (Milios, 2010; Sjölund \& Jump, 2013). There are 
species that regenerate using both sprouts and seeds (Kozlowski, 2002). Fagus sylvatica L. s.l. is one of them (Papalexandris \& Milios, 2010; Cullotta et al., 2015; Leonardsson \& Götmark, 2015; Cullotta et al., 2016).

Fagus sylvatica is a species that is susceptible to drought and will possibly retreat from many areas as a result of climate change (Packham et al., 2012; Penuelas et al., 2007). Papalexandris and Milios (2010), studying low elevation beech stands in northeastern Greece, reported that sprouting can support the maintenance of beech stands, and proposed the usage of seedling sprouts in the silvicultural systems applied in the area. However, beech can have a multistemmed form as a result of extreme ecological conditions (Cullotta et al., 2015; Cullotta et al., 2016), it also has the ability to produce stump sprouts after tree cutting (Papalexandris \& Milios, 2010; Leonardsson \& Götmark, 2015). This ability is not limited to young ages (seedling and saplings) but continues for the first decades of the tree life. Thus, in many areas of southern Europe, the coppice system was used in beech stands mainly in the past (Bartha et al., 2008; Mariotti et al., 2017, Chianucci et al., 2016). The rotation of these coppices in some areas of Italy reached 27 to 30 years (Bartha et al., 2008; Chianucci et al., 2016). Fagus sylvatica trees with rather large dimensions can also sprout. According to Leonardsson and Götmark (2015), the mean diameter of more or less shaded living beech stumps, 9 years after thinning was between 35 and $40 \mathrm{~cm}$. However, the living sprouts were few.

Rot can enter to sprouts from the mother stumps, but this risk is not the same for all species (Oliver \& Larson, 1996; Smith et al., 1997). In coppices, in order to avoid the spread of decay from the mother stump to the new sprouts, the stump must be cut at a low height and the cut surface has to be properly shaped (Dafis, 1992). According to Smith et al. (1997), even though in some cases trees that come from sprouts are not straight, sprouts that emerge from small stumps having a diameter less than $5 \mathrm{~cm}$ (seedling sprouts) tend to be straighter than seedlings since these sprouts overcome faster the zone of height where deformities are usually created. Moreover, in these sprouts, the risk of the heart rot expansion from the stump to the new sprout is considerably reduced (Smith et al., 1997).

Sprouts (from stumps and roots) generally show higher growth rates than seedlings (Kennard et al., 2002; Farahat \& Lechowicz, 2013). However, there are no research results on the growth of sprouts emerging from small dimension stumps of $F$ sylvati$c a$ under shade. Moreover, the growth superiority of stump sprouts, compared to that of seedlings, has not been investigated under shade for $F$. sylvatica. The knowledge of height growth competitiveness of stump sprouts that emerge from small dimension stumps against seed origin regeneration plants will be one of the basis for the development of special silvicultural treatments for the regeneration of beech stands. These treatments will be necessary for the conservation of $F$. sylvatica in marginal areas of the species range.

The aims of this study were: a) to analyze the growth of seed origin saplings and young stump sprouts that emerged from small dimension stumps, under different shade and site conditions in low elevation $F$. sylvatica stands in northeastern Greece and b) to recommend silvicultural treatments for the incorporation of stump sprouts in the regeneration process of beech stands, which are growing in analogous ecological conditions.

\section{Materials and methods}

\section{Site characteristics}

The present study was conducted in an area of 196 ha that is covered by uneven-aged low elevation Fagus sylvatica s.l. stands where Quercus pendunculiflora appears in the form of sparsely scattered individuals. In part of the area, there is a mixed formation of $F$. sylvatica $-Q$. pendunculiflora in the form of groups of trees (Milios \& Papalexandris, 2008; Papalexandris \& Milios, 2010). The elevation of the study area ranges from 475 to $700 \mathrm{~m}$ a. s. $1 .\left(41^{\circ} 09^{\prime} \mathrm{N}, 26^{\circ} 03^{\prime} \mathrm{E}\right)$, the soils are sandy to sandy-clay, while the parent material is gneiss. According to the closest meteorological station, the annual precipitation has an average of 934.71 and the mean annual temperature is $12.56^{\circ} \mathrm{C}$ (Iloriki, 2006). The dominant slopes are $5-20 \%$ and there is a high variability in soil and micro topography conditions, resulting in changes of site conditions at rather small spatial scales.

The beech stands exhibit an irregular and uneven-aged structure (Papalexandris \& Milios, 2009). In the area where F. sylvatica dominates, the stand volume ranges from 304.9 to $313.6 \mathrm{~m}^{3}$ (Iloriki, 2006). Low intensity thinnings and regeneration fellings have been made in the past decades in the area. The last silvicultural treatments (thinnings or cuttings) were made 7 and 9 years (in different parts of the study area) before the data acquisition period (see also Milios \& Papalexandris, 2008).

Seed origin regeneration is the predominant form of regeneration. However, sprouts represent a significant part of regeneration plants in medium productivity sites. The sprouts are stump sprouts (emerged mostly by small dimension stumps) and root sprouts. The stump sprouts are mainly the result of the cutting of small dimension trees (seedlings and saplings). For more detailed information for the study area see Papalexandris and Milios (2010). 


\section{Methods}

During the summer of 2007, in the frame of a study regarding the influence of shade and site on the seedling density (see Milios \& Papalexandris, 2008), 180 points were randomly selected in the $F$. sylvatica stands. Ninety of them were selected in medium productivity sites, and 90 in good productivity sites. The points were selected both in areas where regeneration cuttings and thinnings were applied.

In order to characterize the site productivity of a small area, the approach of Papalexandris and Milios (2010) was followed. In particular, the shape (concave or convex) of the terrain as a total soil depth surrogate, the location on the slope, the surface soil depth where organic matter was intermingled with inorganic soil, and the occurrence of a source of water in the vicinity (stream) were used (Dafis, 1986; Barnes et al., 1998; Milios, 2004; Adamopoulos et al., 2009). Two site productivity site types were distinguished. Site type A represents the good productivity sites and site type B represents the medium productivity sites. The concave terrain, as well as the lower part of the slope, represented good productivity sites. Moreover, in cases that there were doubts regarding the site productivity classification, resulting from the topographical characteristics, the surface soil depth where organic matter was intermingled with inorganic soil and the occurrence of a source of water in the vicinity (stream) were used as the main factors for site productivity determination. Papalexandris and Milios (2010) found a soil depth up to $30 \mathrm{~cm}$ in site type B and of over $40 \mathrm{~cm}$ in site type A.

The shade conditions were determined using hemispherical photography. In each point, we took hemispherical photograph at a height of $1.5 \mathrm{~m}$ with a Nikon Coolpix 900 digital camera with fisheye lens $\left(180^{\circ}\right.$ field of view) and a self-leveling mount. The photos were taken during August of 2007 under a clear sky after sunset or before sunrise. Photos were processed with the Hemiview software (Delta T Devices, Cambridge, UK). For each photo, the Visible sky (Vs) value was calculated (see also Milios \& Papalexandris, 2008). Visible sky is the part of the sky that is visible as the ratio of the entire hemisphere when it is viewed from a single point (Hale, 2001). Visible sky (or Gap fraction or canopy openness) is a useful index that is related to the light reaches a point (Jennings, 1999; Hale, 2001; Montgomery, 2004). The reason for which the Visible sky index was selected as a measure of shade was that it gives information regarding growth conditions of regeneration plants and based on that, manipulations of the canopy can be made (see Jennings, 1999).

A classification of all photos was made based on their Vs. For each one of the two site types, 10 photographs with Vs value lower than 0.08 , and 10 with a
Table 1. Characteristics of the selected photos

\begin{tabular}{lccccc}
\hline \multirow{2}{*}{ Classification of photos } & \multicolumn{4}{c}{ Visible sky } & \multirow{2}{*}{ N } \\
\cline { 2 - 5 } & Mean & S. D. & Min & Max & \\
\hline S. type A Vs $<0.08$ & 0.058 & 0.013 & 0.039 & 0.077 & 10 \\
S. type B Vs $<0.08$ & 0.054 & 0.010 & 0.033 & 0.066 & 10 \\
S. type A 0.08 $<$ Vs $<0.20$ & 0.111 & 0.031 & 0.081 & 0.183 & 10 \\
S. type B 0.08< Vs $<0.20$ & 0.108 & 0.015 & 0.93 & 0.146 & 10 \\
\hline
\end{tabular}

S.D. - standard deviation.

value being higher than 0.08 and lower than 0.2 were selected. The selection of photos was made in order for the photographs of site type A with Vs $<0.08$ to have more or less the same mean Vs value with the photographs of site type B with Vs $<0.08$ (Table 1). The same process was followed for the photographs with Vs values between 0.08 and 0.20 . The adoption of those limits was based on the range and the distribution of the taken photos in order to have two groups of photographs that represent two different conditions (degrees) of shade. Moreover, other prerequisites for the selection of a photo were to had been taken in points: a) that were under rather homogenous canopy and b) where there were seed origin saplings and stump sprouts up to $1.5 \mathrm{~m}$ in height in the vicinity.

For each of the forty aforementioned selected photos, a circular plot having a radius of $2.5 \mathrm{~m}$ was established. The center of the plot was the point from which the photo was taken.

For each plot, the site characterization was confirmed by the determination of the soil depth. The plots of site type B had a soil depth up to approximately $30 \mathrm{~cm}$, while the plots of site type A had a soil depth of over $40 \mathrm{~cm}$ (see also Papalexandris \& Milios, 2010).

From each plot, two seed origin saplings and two stump sprouts up to approximately $1.50 \mathrm{~m}$ in height were cut, in the context of another study regarding the growth of saplings. These saplings had to be robust and taller compared to their competitors (if there were any). Moreover, the sprouts had to be emerged from stumps having a basal diameter up to $7 \mathrm{~cm}$. The upper limit of a mother stump diameter, in order a sprout to be selected, was set to $7 \mathrm{~cm}$, since the stump dimensions influence the growth of sprouts (Oliver \& Larson, 1996; Lockhart \& Chambers, 2007; O'Hara, 2014). As a result, a great range of mother stump dimensions could influence the results of a study on sprout growth. However, in the established plots, all the robust sprouts up to $1.50 \mathrm{~m}$ in height emerged from stumps having a basal diameter lower than $7 \mathrm{~cm}$.

In the plots where there were more than two saplings in an origin category (seed origin or stump sprout) that fulfilled the selection prerequisites (height, stump basal diameter for sprouts, robustness, taller than their competitors), the saplings of 
this category were randomly selected. However, in almost all cases the four saplings that were cut (two seed origin and two stump sprouts) were the only saplings that fulfilled the selection prerequisites. The height of the sprout origin saplings was measured at the point where the sapling arose from the mother stump. In each sapling, a cross section was cut at their base. All cross sections were sanded and the number of annual growth rings was counted in each section.

In the frame of the present study, the selected saplings that a) were in a distance up to $1.8 \mathrm{~m}$ from the point where the photo was taken, and b) had established in the year or in the next year from the time when the last silvicultural treatment had taken place, were considered that were established and grown under the same light conditions. In total, 56 of the cut seed and sprout origin saplings fulfilled the above mentioned prerequisites (distance from the point of photo and time of establishment). The age of those saplings ranged from seven to ten years.

The saplings that were established near the point where the Vs values (calculated from the photo taken from each point) were lower than 0.08 , were considered that have been established and grew under deep shade conditions. On the contrary, the saplings that were established near the point where the Vs values were between 0.08 and 0.2 , were considered that have been established and grew under moderate shade conditions. Thus, the 56 saplings were classified in eight categories: These were 1) saplings of seed origin growing under moderate shade in site type A, 2) saplings of sprout origin (stump sprouts) growing under moderate shade in site type A, 3) saplings of seed origin growing under deep shade in site type A, 4) saplings of sprout origin growing under deep shade in site type A, 5) saplings of seed origin growing under moderate shade in site type $B, 6$ ) saplings of sprout origin (stump sprouts) growing under moderate shade in site type $B, 7$ ) saplings of seed origin growing under deep shade in site type $\mathrm{B}$, and 8) saplings of sprout origin growing under deep shade in site type B.
For each of the 56 selected saplings the mean annual height increment (MAHI) was calculated dividing the height of the sapling by the age of its base (Husch, 1982).

\section{Statistical Analysis}

Tree MAHI data of the different sapling categories were compared using the Duncan test, since the data followed the normal distribution and exhibited homogeneity of variances (Illowsky \& Dean, 2008). The seed origin saplings that were established and grew under deep shade in site type B were not included in the comparison, since only two of the saplings that were cut belonged to that sapling category.

\section{Results}

The mean MAHI of the seed and sprout origin saplings that were established and grew in the different shade conditions in the two site types ranged from $11.02 \mathrm{~cm}$, in seed origin saplings that grew in moderate shade in site type $B$, to $13.56 \mathrm{~cm}$ in sprout origin saplings that grew in moderate shade in site type A (Table 2). Almost all sprout origin saplings emerged from stumps having a diameter of lower than $5 \mathrm{~cm}$.

The sprout origin saplings growing under moderate shade in site type A had the highest MAHI $(\mathrm{p}<0.05)$, compared to the rest six categories of saplings. On the other hand, there were no differences among the other categories of seed and sprout origin saplings (Table 2 ).

\section{Discussion}

The shade regime that created unfavorable growth conditions, probably led to low growth rates and to absence of MAHI differences ( $p>0.05$ ) among the (compared) categories of the seed origin plants (Table

Table 2. Mean MAHI of saplings of different origin, growing in different combinations of site productivity and shade conditions

\begin{tabular}{|c|c|c|c|}
\hline \multirow{2}{*}{ Categories of saplings } & \multicolumn{3}{|l|}{ MAHI } \\
\hline & Mean MAHI (cm/year) & S.D. & $\mathrm{N}$ \\
\hline Seed origin saplings growing under moderate shade in site type A & $11.21^{\mathrm{b}}$ & 0.485 & 5 \\
\hline Sprout origin saplings growing under moderate shade in site type A & $13.56^{\mathrm{a}}$ & 0.767 & 11 \\
\hline Seed origin saplings growing under deep shade in site type A & $11.67^{\mathrm{b}}$ & 1.330 & 5 \\
\hline Sprout origin saplings growing under deep shade in site type A & $11.47^{\mathrm{b}}$ & 0.892 & 4 \\
\hline Seed origin saplings growing under moderate shade in site type B & $11.02^{\mathrm{b}}$ & 1.442 & 6 \\
\hline Sprout origin saplings growing under moderate shade in site type B & $11.15^{\mathrm{b}}$ & 1.267 & 12 \\
\hline Sprout origin saplings growing under deep shade in site type B & $11.14^{\mathrm{b}}$ & 1.609 & 11 \\
\hline
\end{tabular}

Means followed by a different letter are statistically different for $\mathrm{P}<0.05$.

S.D. - standard deviation.

MAHI - mean annual height increment. 
2). According to Collet et al. (2001), the reduced growth of beech seedlings under low light conditions in combination with their capacity to survive under such harsh conditions, gives the ability of young and old seedling coexistence in a regeneration patch.

Growth of stump sprouts is influenced by a complex combination of factors. The first period after the time of stump sprout emergence, the height growth of sprouts is supported by the movement of photosynthesis products from the stump and the preexisting root system (Wilson, 1968; Kennard et al., 2002). Moreover, after the depletion of the carbohydrate reserves of the sprouting system, the preexisting root system can provide more water and nutrients to the sprout as a result of its larger size (Kennard et al., 2002). According to Lockhart and Chambers (2007), the high early height growth of stump sprouts gradually decreases over time, as sprout dimensions and root system comes into balance. The above-mentioned stump sprout traits probably contributed to the higher MAHI $(\mathrm{p}<0.05)$ that was exhibited by the sprouts, growing under moderate shade in site type A, compared to the other sapling categories (Table 2).

The dimensions of the parent tree may have a negative effect in the cumulative growth of sprouts if a rather small photosynthesis production of sprouts has to maintain respiration of a mother root system having large dimensions. This possibly can result in lower amounts of energy available for sprout growth (Peterson \& Picket, 1991; Masaka et al., 2004). In the present study, the mother trees of the sprouts had small dimensions, as a result, the respiration needs of the mother root systems are considered rather low.

The absence of a (practically) high height growth (MAHI) difference between sprouts growing under moderate shade in site type A and the other (compared) seed and sprout origin saplings, was the result of the low light environment. After the depletion of the carbohydrate reserves of the preexisting root system and the stump, which supported sprout growth, the root system had the ability to provide more water and nutrients to the sprouts. In addition, the respiration needs of the root system were probably low. However, stump sprouts did not exhibit rapid height growth. Shade conditions reduced the photosynthetic production of sprouts and, thus, their ability for high height growth rates. Only in the favorable site conditions of site type A, under the moderate shade conditions, sprouts managed to exhibit higher height growth rates, compared to seed origin saplings $(p<0.05)$. On the contrary, in the harsher conditions created under deep shade in site type A, and in the two shade regimes of site type $B$, sprout origin saplings did not show higher MAHI than the categories of seed origin saplings that grew under the two shade regimes in site type $A$ and under moderate shade in site type B $(p>0.05)$ (Table 2$)$.
Light conditions seem to influence the growth performance of other species sprouts too. Lockhart and Chambers (2007) reported that, after a plantation thinning, as light is reduced a lower height growth of Quercus pagoda stump sprouts should be expected. O'Hara et al. (2007) mentioned that, the light conditions following cuttings and the existing reserves at the time of cutting, have a significant effect in the vigor of the sprout clumps of Sequoia sempervirens. As time from the year of sprout emergence passes, light conditions become the factor that determines the growth of sprouts (O'Hara \& Berrill, 2010).

The height growth of sprouts that grew under moderate shade in site type A cannot be considered very low, since it was not much lower from the growth of the nine years old $F$. sylvatica sprouts that emerged after a conservation thinning in Sweden (Leonardsson \& Götmark, 2015). Those sprouts grew under more favorable light conditions than the saplings of the present study and emerged from stumps having larger dimensions. Moreover, Milios et al. (2012) reported that more than $95 \%$ of the seed origin saplings, having an age of between 5 and 44 years, which were established under an open canopy in medium productivity sites in northeastern Greece, had a MAHI lower than $20 \mathrm{~cm} /$ year.

Another factor that probably affected sprout growth was that the sprouts emerged as a result of silvicultural treatments that were made in summer during the growth period.

According to Kozlowski et al. (1991), sprouting usually is not so vigorous when the cutting takes place in the period when reserves are low (early summer). Moreover, Ducrey and Turrel (1992) reported that stump growth is weaker in a coppice of Quercus ilex, when the cutting was made in the growing season. They also mentioned that the cutting period for the best sprout growth was that just before the starting of the growing period.

More research is needed in order to determine the growth performance of $F$. sylvatica sprouts under different growth conditions. The influence of factors like the mother stump dimensions as well as the sprout age on the height growth of beech sprouts must be analyzed in future studies.

\section{Conclusions and implications for forest practice}

Sprouts that grew in deep shade in both site types, and in moderate shade in site type B, exhibited height growth (MAHI) analogous to seed origin plants growing under moderate and deep shade in site type A, and under moderate shade in site type B. Consequently, sprouts can be used in various types and forms of shelterwood silvicultural systems, 
where regeneration plants are established and grow (at least the first years of their life) under shade conditions. Moreover, even though it is of no practical significance (the MAHI difference was about $2-2.5$ $\mathrm{cm}$ /year), stump sprouts growing under moderate shade in site type A, showed higher MAHI than all the other (compared) categories of seed and sprout origin saplings. A few years after the emergence of sprouts, as regeneration cuttings proceed through the gradual removal of the mother trees, sprouts will probably exhibit high growth rates, as a result of the improved light conditions and their preexisting root system (see discussion). O'Hara et al. (2007), in order to promote height growth of Sequoia sempervirens sprouts, suggest the increase of light to approximately $50 \%$ of the above canopy light, through silvicultural treatments.

Finally, in order to have a robust sprout growth, the cuttings for the emergence of stumps should be made just before the beginning of the growth period.

\section{Acknowledgements}

We thank the Forest Service of Soufli for their cooperation.

\section{References}

Adamopoulos S, Milios E, Doganos D \& Bistinas I (2009) Ring width, latewood proportion and dry density in stems of Pinus brutia Ten. European Journal of Wood and Wood Products 67: 471-477. doi:10.1007/s00107-009-0345-x.

Barnes BV, Zak DR, Denton SR \& Spurr SH (1998) Forest ecology. 4th. John Willey \& Sons Inc. New York, USA.

Bartha S, Merolli A, Campetella G \& Canullo R (2008) Changes of vascular plant diversity along a chronosequence of beech coppice stands, central Apennines, Italy. Plant Biosystems 142: 572-583. doi:10.1080/11263500802410926.

Batziou M, Milios E \& Kitikidou K (2017) Is diameter at the base of the root collar a key characteristic of seedling sprouts in a Quercus pubescens-Quercus frainetto grazed forest in north-eastern Greece? A morphological analysis. New Forests 48: 1-16. doi:10.1007/s11056-016-9552-6.

Bond W \& Midgley JJ (2001) Ecology of sprouting in woody plants: the persistence niche. Trends in Ecology and Evolution 16: 45-51.

Chianucci F, Salvati L, Giannini T, Chiavetta U, Corona P \& Cutini A (2016) Long-term response to thinning in a beech (Fagus sylvatica L.) coppice stand under conversion to high forest in Central Italy. Silva Fennica 50: 1549. doi:doi. org/10.14214/sf.1549.
Collet C, Lanter O \& Pardos M (2001) Effects of canopy opening on height and diameter growth in naturally regenerated beech seedlings. Annals of Forest Science 58: 127-134.

Cullotta S, Puzzolo V \& Fresta A (2015) The southernmost beech (Fagus sylvatica) forests of Europe (Mount Etna, Italy): ecology, structural stand-type diversity and management implications. Plant Biosystems 149: 88-99. doi:10.1080/11263504.20 13.814603.

Cullotta S, La Placa G \& Maetzke FG (2016) Effects of traditional coppice practices and microsite conditions on tree health in a European beech forest at its southernmost range. IForest 9: 673-681. doi:10.3832/ifor1603-008.

Dafis S (1986) Forest ecology. Giahoudi Giapouli, Thessaloniki, Greece.

Dafis S (1992) Applied silviculture. Giahoudi Giapouli, Thessaloniki, Greece.

Delta-T Devices Ltd. (1999) HemiView, User Manual. U. K.

Ducrey M \& Turrel M (1992) Influence of cutting methods and dates on stump sprouting in Holm oak (Quercus ilex L.) coppice. Annals of Forest Science 49: 449-464.

Farahat E \& Lechowicz MJ (2013) Functional ecology of growth in seedlings versus root sprouts of Fagus grandifolia Ehrh. Trees 27: 337-340. doi:10.1007/ s00468-012-0781-9.

Hale SE (2001) Light regime beneath Sitka spruce plantations in northern Britain: preliminary results. Forest Ecology and Management 151: 61-66. doi:doi.org/10.1016/S0378-1127(00)00696-4.

Husch B, Miller CI \& Beers TW (1982) Forest mensuration. Wiley, USA.

Illowsky B \& Dean S (2008) Collaborative statistics. Rice University, Houston, Texas USA.

Iloriki EE (2006) Management plant of Deriou -Dadias -Esimis Forest, period: 2006 - 2015. Thessaloniki, Greece.

Jennings SB, Brown ND \& Sheil D (1999) Assessing forest canopies and understory illumination: canopy closure, canopy cover and other measures. Forestry 72: 59-73.

Kennard DK, Gould K, Putz FE, Fredericksen TS \& Morales F (2002) Effect of disturbance intensity on regeneration mechanisms in a tropical dry forest. Forest Ecology and Management 162: 197-208.

Kozlowski TT (2002) Physiological ecology of natural regeneration of harvested and disturbed forest stands: implications for forest management. Forest Ecology and Management 158: 195-221.

Kozlowski TT, Kramer PJ \& Pallardy SG (1991) The physiological ecology of woody plants. Academic Press Inc., San Diego, USA.

Leonardsson J \& Götmark F (2015) Differential survival and growth of stumps in 14 woody species 
after conservation thinning in mixed oak-rich temperate forests. European Journal of Forest Research 134: 199-209. doi:10.1007/s10342-0140843-1.

Lockhart BR \& Chambers JL (2007) Cherrybark oak stump sprout survival and development five years following plantation thinning in the lower Mississippi alluvial valley, USA. New Forests 33: 183192. doi:10.1007/s11056-006-9022-7.

Mariotti B, Alberti G, Maltoni A, Tani A \& Piussi P (2017) Beech coppice conversion to high forest: results from a 31-year experiment in Eastern Pre-Alps. Annals of Forest Science 74: 44. doi:10.1007/s13595-017-0642-1.

Masaka K, Ohno Y \& Yamada K (2004) Recovery of canopy trees and root collar sprout growth in response to changes in the condition of the parent tree after a fire in a cool-temperate forest. Journal of Forest Research 9: 271-275. doi:10.1007/ s10310-004-0090-2.

Milios E \& Papalexandris C (2008) The influence of shade and site productivity on the seedling density in low elevation stands of Fagus sylvatica L. s.l. located in north-eastern Greece. Lesnicky casopis. Forestry Journal 54: 13-20.

Milios E (2004) The influence of stand development process on the height and volume growth of dominant Fagus sylvatica L. s.l. trees in the central Rhodope Mountains of north-eastern Greece. Forestry 77 : $17-26$.

Milios E, Kitikidou K, Stampoulidis A, Gotsi M, Ketipis V \& Vrizas K (2012) Analysis of Fagus sylvatica L. s.l. regeneration formations under open canopies in the central Rhodope mountains of north-eastern Greece, a preliminary study. Proceedings of the International Scientific Conference: Forests in the Future - Sustainable Use Risks and Challenges (ed. by L Rakonjac) Institute of Forestry, Belgrade, Serbia 4-5 October 2012, pp. 537-543.

Milios E, Pipinis E, Kitikidou K, Batziou M, Chatzakis $S$ \& Akritidou S (2014) Are sprouts the dominant form of regeneration in a lowland Quercus pubescens-Quercus frainetto remnant forest in Northeastern Greece? A regeneration analysis in the context of grazing. New Forests 45: 165-177. doi:10.1007/s11056-013-9399-z.

Milios E (2010) Facilitation process and sprouting ability as silvicultural tools in the frame of climate change. Proceedings of Plenary Lectures of the International Scientific Conference: Forest Ecosystems and Climate Changes (ed. by L Rakonjac) Institute of Forestry, Belgrade, Serbia 9-10 March 2010, pp. 137-142.

Montgomery RA (2004) Effects of understory foliage on patterns of light attenuation near the forest floor. Biotropica 36: 33-39.
O'Hara KL (2014) Multiaged silviculture: managing for complex forest stand structures. Oxford University Press, Oxford, United Kingdom.

O'Hara KL \& Berrill JP (2010) Dynamics of coast redwood sprout clump development in variable light environments. Journal of Forest Research 15: 131-139. doi:10.1007/s10310-009-0166-0.

O'Hara KL, Stancioiu PT \& Spencer MA (2007) Understory stump sprout development under variable canopy density and leaf area in coast redwood. Forest Ecology and Management 244: 76-85.

Oliver CD \& Larson BC (1996) Forest stand dynamics. John Wiley \& Sons Inc., New York, USA.

Packham JR, Thomas PA, Atkinson MD \& Degen T (2012) Biological flora of the British Isles: Fagus sylvatica L. Journal of Ecology 100: 1557-1608. doi:10.1111/j.1365-2745.2012.02017.x.

Papalexandris C \& Milios E (2009) Structure analysis and description of shade - light conditions in low elevation Fagus sylvatica L. s.l. stands located in the central part of the Evros region in northeast of Greece. Scientific Annals of the Department of Forestry and Management of the Environment and Natural Resources, Orestiada, Greece 2: 83-97.

Papalexandris C \& Milios E (2010) Analysis of natural Fagus sylvatica L. s.l. regeneration in low elevation stands located in the central part of the Evros region in northeastern Greece: is sprout origin regeneration significant for species maintenance? Plant Biosystems 144: 784-792. doi:10.1080/112 63504.2010 .513867$.

Pausas JG, Pratt RB, Keeley JE, Jacobsen AL, Ramirez AR, Vilagrosa A, Paula S, Kaneakua-Pia IN \& Davis SD (2016) Towards understanding resprouting at the global scale. New Phytologist 209: 945954. doi:10.1111/nph.13644.

Penuelas J, Ogaya R, Boada M \& Jump AS (2007) Migration, invasion and decline: changes in recruitment and forest structure in a warming-linked shift of European beech forest in Catalonia. Ecography 30: 829-837. doi:10.1111/j.2007.09067590.05247.x.

Peterson CJ \& Pickett STA (1991) Treefall and resprouting following catastrophic windthrow in an old-growth hemlock-hardwoods forest. Forest Ecology and Management 42: 205-217.

Sjölund MJ \& Jump AS (2013) The benefits and hazards of exploiting vegetative regeneration for forest conservation management in a warming world. Forestry 86: 503-513. doi:10.1093/forestry/cpt030.

Smith DM, Larson BC, Kelty MJ \& Ashton PMS (1997) The practice of silviculture. Applied forest ecology. John Wiley \& Sons Inc, New York, USA.

Wilson BF (1968) Red maple stump sprouts: development the first year. Harvard Forest Paper 18: $1-10$. 